\title{
Verbal and non-verbal creativity of the students of the Conservatory
}

\author{
Ekaterina Belousova ${ }^{1, *}$, Ekaterina Kryazhkova ${ }^{1}$, Lazar Stošić ${ }^{2}$ \\ ${ }^{1}$ Don State Technical University, Gagarin sq, 1, Rostov- on-Don, 344003, Russia \\ ${ }^{3}$ Institute of management and knowledge, str. Jane Sandanski, 3/2/13, 1000 Skopje, Republic of \\ Macedonia
}

\begin{abstract}
The article deals with the features of verbal and non-verbal creativity of Conservatory students. The study used: methods for diagnosing verbal creativity (adapted version of The S. Mednik RAT test), methods for diagnosing nonverbal creativity (short version of the Torrens test), and the "picture of the world" method. The purpose of the study was to study the features of verbal and non-verbal creativity and the image of the world of students, as well as to study their relationships. Three groups of students: low, moderate, and high level of creativity, which describes the inherent types of the world picture, the features of the development of the creativity indices. It was shown that there are significant differences in the development of verbal creativity in the originality index for students with medium and low, medium and high, low and high levels of nonverbal creativity, and in the uniqueness index for students with high and low levels of nonverbal creativity. It was found that for students with a low level of creativity, the landscape picture of the world is more pronounced, and for students with a high level of nonverbal creativity, the abstract picture of the world is more pronounced. Some significant relationships between creativity and the features of the students ' worldview are highlighted.
\end{abstract}

\section{Introduction}

Identifying the creativity of students is an extremely important problem for education, because it allows you to build different individual trajectories of learning and development.

In recent years, the concept of creativity has acquired social significance, as it has become one of the social requirements that society imposes on young people. This problem is especially relevant for students, in whose educational and communicative environment creativity is developing. In psychology, creativity is considered as a complex formation, which, according to D. Gilford [1], E. P. Torrens [2], can be considered as an independent phenomenon, independent of the intellect. Sternberg [3] believes that creativity acts both as a high level of intelligence and as creative abilities. R. Sternberg presented his views on the development of creativity in the educational process in an article that reveals the possibilities and limitations of this process [4]. A number of authors [5-7] it is believed that there are many definitions of creativity, which have their own specific features.

\footnotetext{
*Corresponding author: katy-belousova@mail.ru
} 
At the student age, the image of the world is formed [8,9], and creative motivation and creativity are intensively developed $[10,11]$. In this regard, it is of great interest to study creativity and the image of the world among students studying in various specialties, in particular, those receiving education at the Conservatory. There are interesting studies showing strategies for teaching Conservatory students, the role of critical thinking strategies in effective interaction between teachers and students, and the development of musical creativity [12]. The authors [13] studied the role of creativity in the training of Conservatory students and the formation of their identity, which resulted in an understanding of the need to develop creative activities in the educational process, the organization of dialogue, and joint creativity.

The purpose of our work was to study the features of the development of verbal and nonverbal creativity and the worldview of students of conservatism and to study the relationship between them.

\section{Materials and Methods}

To achieve the main objectives of the study, it was decided to use the following methods: the method for diagnosing verbal creativity (adapted version of The S. Mednik RAT test) [14], the method for diagnosing nonverbal creativity (short version of the Torrens test) [2], [14], and the "world mapping" method [15].

The object of the study was students of the state Conservatory of Rostov-on-don. The sample consisted of 65 students of 4-5 courses and postgraduate studies of the Rostov State Conservatory. The sample included 42 girls and 23 boys.

A method for diagnosing nonverbal creativity or a short version of the E. P. Torrens test, which consists of six images with a set of different elements (lines). The Respondent is asked to draw a picture based on these elements to get a complete image. The test uses indicators of creativity: originality, or dissimilarity of the created image to the images of other people; uniqueness, which was determined by comparing the resulting drawing with the drawings available in the Atlas, in the absence of such a drawing was considered unique [14].

Identification of the level of verbal creativity of students was carried out using the verbal creativity test (adapted version of The S. Mednik RAT test), considered as a process of recombining elements of the situation. The test contains 20 word triads (word triads) whose elements belong to mutually distant associative regions. For each triad of words, you need to find a fourth word that combines the elements in such a way that it forms a certain phrase with each of these three words. The method involves the use of the following indexes:

the index of originality - the sum of the indices of the original individual responses to the total number of responses; an index of the uniqueness of the answers is equal with respect to the number of unique responses to total responses; index of ductively - the ratio of the number of responses to the number of tasks [14].

To study the features of the image of the world of musicians with different levels of creativity, we used the Graphic test "picture of the world", which allows us to determine the features of the depicted picture of the world by five main selected types of drawing: "Planetary"includes an image of the globe, other planets of the Solar system - a cognitive picture of the world, in the form of generally accepted normative knowledge acquired at school; "Landscape"-in the form of an urban or rural landscape with the presence of people, animals, trees, flowers, etc.; "Immediate environment" - the situation around yourself, your home, as it really is, or situational;" Mediated, or metaphorical "-conveys a complex semantic content, presented in the form of a complex image;" Abstract", differs in laconism of construction-in the form of an abstract image, sign, symbol. When processing the results, we used the figure indicators used in the projective techniques [15], [16]. 
Methods of mathematical statistics were used in the study: Kolmogorov-Smirnov test, method for determining the significance of differences, Kruskal-Wallis H-test, Spearman's rank correlation method [17].

\section{Results}

In accordance with one of the objectives of our research, we conducted a diagnosis of nonverbal and verbal creativity of Conservatory students.

Analysis of the obtained data on the method of diagnostics of nonverbal creativeness of TORRANCE allowed us to obtain the results presented in table 1. On the basis of mathematical processing were obtained the average values of the indexes of non-verbal creativity.

Table 1. The averages of non-verbal creativity of the students of the Conservatory.

\begin{tabular}{|c|c|c|c|c|}
\hline Indexes & Mean & Std. Deviation & Maximum & Minimum \\
\hline Originality index & 0.88 & 0.145 & 1 & 0.73 \\
\hline Uniqueness index & 4.73 & 1.428 & 6 & 3.33 \\
\hline
\end{tabular}

Using the method of constructing confidence intervals, we identified three groups of students with high (17\%), medium (35\%) and low (48\%) levels of nonverbal creativity.

Students with a high level of nonverbal creativity have high scores on the uniqueness index and the originality index. Thus, we can say that students with a high level of nonverbal creativity are able to improve the object by adding details, produce a variety of ideas, respond to stimuli in a non-standard way, and find original, creative ways to solve nonverbal tasks assigned to them.

Students with an average level of nonverbal creativity have average scores on the uniqueness index and the originality index. We believe that students with an average level of nonverbal creativity are generally able to find original solutions to problems and create something new. However, they have a standard approach to the problem.

Students with a low level of nonverbal creativity have low indicators on the uniqueness index and the originality index, which indicates a rather low ability to find a unique, creative solution to the nonverbal tasks assigned to them. in General, there is a standard, stereotypical approach to the problem.

According to the method of diagnostics of verbal creativity adapted to The S. Mednik RAT test, the results presented in table 2 were obtained for Conservatory students with different levels of nonverbal creativity.

Table 2. Average values of verbal creativity of Conservatory students with different levels of nonverbal creativity.

\begin{tabular}{|l|l|l|l|l|l|l|l|l|l|l|l|l|}
\hline \multirow{2}{*}{$\begin{array}{l}\text { Conservato } \\
\text { ry students }\end{array}$} & \multicolumn{4}{|l|}{ Number of associations } & \multicolumn{4}{|l|}{ Originality index } & \multicolumn{3}{|c|}{ Uniqueness Index } \\
\cline { 2 - 13 } & $\mathbf{x}$ & $\mathbf{m i n}$ & $\mathbf{m a x}$ & $\mathbf{x}$ & $\boldsymbol{\delta}$ & $\begin{array}{l}\mathbf{m i} \\
\mathbf{n}\end{array}$ & $\begin{array}{l}\mathbf{m a} \\
\mathbf{x}\end{array}$ & $\mathbf{x}$ & $\begin{array}{l}\boldsymbol{\delta} \\
\mathbf{n i}\end{array}$ & $\mathbf{m a x}$ \\
\hline Low level & 20.1 & 0.4 & $\begin{array}{l}19.7 \\
8\end{array}$ & $\begin{array}{l}20.5 \\
8\end{array}$ & $\begin{array}{l}0.3 \\
3\end{array}$ & $\begin{array}{l}0.0 \\
7\end{array}$ & $\begin{array}{l}0.2 \\
6\end{array}$ & 0.4 & 3 & $\begin{array}{l}1 . \\
4\end{array}$ & 1.6 & 4.4 \\
\hline $\begin{array}{l}\text { Average } \\
\text { level }\end{array}$ & $\begin{array}{l}21.4 \\
1\end{array}$ & 5.6 & $\begin{array}{l}15.8 \\
1\end{array}$ & 27 & $\begin{array}{l}0.4 \\
4\end{array}$ & $\begin{array}{l}0.1 \\
4\end{array}$ & 0.3 & $\begin{array}{l}0.5 \\
8\end{array}$ & $\begin{array}{l}5.0 \\
8\end{array}$ & $\begin{array}{l}3 . \\
8\end{array}$ & $\begin{array}{l}1.2 \\
8\end{array}$ & 8.88 \\
\hline High level & 22.4 & $\begin{array}{l}4.6 \\
4\end{array}$ & 17.7 & $\begin{array}{l}27.0 \\
4\end{array}$ & $\begin{array}{l}0.5 \\
8\end{array}$ & $\begin{array}{l}0.2 \\
1\end{array}$ & $\begin{array}{l}0.3 \\
8\end{array}$ & $\begin{array}{l}0.7 \\
9\end{array}$ & $\begin{array}{l}7.8 \\
3\end{array}$ & $\begin{array}{l}5 . \\
4\end{array}$ & $\begin{array}{l}2.4 \\
3\end{array}$ & $\begin{array}{l}13.2 \\
3\end{array}$ \\
\hline
\end{tabular}

Differences are significant in the originality index for students with low and medium levels of nonverbal creativity $(\chi 2=5.066 ; \chi 2=3.841$ with $p=0.05)$. It can be said that students with an average level of nonverbal creativity have a higher originality index compared to 
students with a low level. Thus, students with an average level of nonverbal creativity are characterized by verbal creativity and are able to find non-standard solutions.

Our study revealed significant differences in students with average and high levels of nonverbal creativity on the index of originality $(\chi 2=4,229 ; \chi 2=3,841$ at $\mathrm{p}=0.05)$. Thus, students with a high level of nonverbal creativity have a higher originality index than students with an average level. We can say that students with a high level of nonverbal creativity are characterized by the desire to go beyond the problem, to find new, original solutions.

There were also significant differences in the uniqueness index $(\chi 2=10.216 ; \chi 2=6.635$ at $\mathrm{p}=0.01)$ and the originality index $(\chi 2=11.506 ; \chi 2=6.635$ at $\mathrm{p}=0.01)$ among students with high and low levels of nonverbal creativity.

In accordance with one of the tasks of our research, we used the "World picture" method.

According to the "Picture of the world" test, students of the Conservatory received the results presented in table 3 .

Table 3. The main types of drawings "picture of the world" for Conservatory students with low, medium and high levels of non-verbal creativity (\%).

\begin{tabular}{|l|c|c|c|c|c|}
\hline $\begin{array}{c}\text { Conservatory } \\
\text { students }\end{array}$ & Planetary & Landscape & $\begin{array}{c}\text { Immediate } \\
\text { environment }\end{array}$ & Metaphysical & Abstract \\
\hline Low level & 2 & 9 & 0 & 4 & 2 \\
\hline Average level & 5 & 14 & 2 & 14 & 0 \\
\hline High level & 4 & 8 & 2 & 17 & 17 \\
\hline
\end{tabular}

Analysis of the results shown in table 3 allows us to conclude that students with a low level of creativity have a more pronounced landscape picture of the world than students with a high level of creativity. Differences in the landscape picture of the world are significant $\left(\chi 2=4,809 ; \chi^{2}=3,841\right.$ at $\left.p=0.05\right)$. We believe that the majority of students with a low level of nonverbal creativity have the image of the world represented by the desired picture of their environment. This shows that for students with a low level of nonverbal creativity, relationships with others and close people are important, which affects the perception of the world.

Students with a high level of nonverbal creativity have a more pronounced abstract picture of the world than students with an average level of nonverbal creativity. Differences in the abstract picture of the world are significant $(\chi 2=10.059 ; \chi 2=6.635$ for $p=0.01)$. We believe that students with a high level of nonverbal creativity have an image of the world represented as an abstract image, sign, or symbol.

The other types of drawings in the three groups of students are expressed approximately the same.

Thus, the analysis of the results shown in table 3, in General, allows us to speak about the predominance of landscape and abstract pictures of the world among music students.

Table 4. Indicators of drawings in Conservatory students with different levels of non-verbal creativity.

\begin{tabular}{|c|c|c|c|c|c|c|c|c|}
\hline \multirow{2}{*}{$\begin{array}{c}\text { Conservator } \\
\text { y students }\end{array}$} & \multicolumn{2}{|c|}{ The size of the picture } & \multicolumn{2}{c|}{ The picture location } & \multicolumn{2}{c|}{ Color scheme } \\
\cline { 2 - 9 } & $\mathbf{d}$ & $\begin{array}{c}\text { Enlarge } \\
\text { l }\end{array}$ & $\begin{array}{c}\text { Decrease } \\
\mathbf{d}\end{array}$ & $\begin{array}{c}\text { Shifte } \\
\mathbf{d} \text { up }\end{array}$ & $\begin{array}{c}\text { Middl } \\
\text { e line }\end{array}$ & $\begin{array}{c}\text { Shifte } \\
\mathbf{d} \\
\text { down }\end{array}$ & $\begin{array}{c}\text { Col } \\
\mathbf{d}\end{array}$ & $\begin{array}{c}\text { War } \\
\mathbf{m}\end{array}$ \\
\hline Low level & 2 & 9 & 0 & 2 & 9 & 0 & 4 & 7 \\
\hline $\begin{array}{c}\text { Average } \\
\text { level }\end{array}$ & 1 & 22 & 0 & 2 & 21 & 0 & 11 & 12 \\
\hline High level & 7 & 22 & 2 & 6 & 25 & 0 & 15 & 16 \\
\hline
\end{tabular}


Students with an average level of nonverbal creativity have a more pronounced indicator of the normal size of the drawing than students with a high level of nonverbal creativity. Differences in the normal size of the figure are significant $(\chi 2=5,233 ; \chi 2=3,841$ at $p=0.05$ ).

The other indicators of the figure are expressed approximately equally in the three groups.

Analysis of the results of a correlation study using Spearman's rank correlation method allows us to identify the existence of certain correlational significant relationships between the "picture of the world", drawing indicators, and the level of creativity of Conservatory students.

It was found that the image of the world of Conservatory students with high and low levels of non-verbal creativity has the following connections, presented in table 5 .

Table 5. Correlations of creativity indices, the type of worldview, and the location of drawings on a sheet.

\begin{tabular}{|c|c|c|c|c|c|c|c|}
\hline \multirow[b]{2}{*}{$\begin{array}{l}\text { World } \\
\text { picture }\end{array}$} & \multicolumn{2}{|c|}{$\begin{array}{c}\text { High level } \\
\text { Non-verbal creativity } \\
\end{array}$} & \multicolumn{5}{|c|}{$\begin{array}{c}\text { Low level } \\
\text { Non-verbal creativity } \\
\end{array}$} \\
\hline & $\begin{array}{c}\text { Enlarge } \\
\text { d } \\
\text { drawing } \\
\text { size }\end{array}$ & $\begin{array}{l}\text { Originalit } \\
y \text { index of } \\
\text { verbal } \\
\text { creativity }\end{array}$ & $\begin{array}{l}\text { Uniquenes } \\
s \text { index of } \\
\text { verbal } \\
\text { creativity }\end{array}$ & $\begin{array}{c}\text { Enlarge } \\
\text { d } \\
\text { drawing } \\
\text { size }\end{array}$ & $\begin{array}{c}\text { Normal } \\
\text { drawin } \\
\text { g size }\end{array}$ & $\begin{array}{l}\text { Drawin } \\
\mathrm{g} \text { at the } \\
\text { top of } \\
\text { the } \\
\text { sheet }\end{array}$ & $\begin{array}{c}\text { Drawin } \\
g \text { in the } \\
\text { middle } \\
\text { of the } \\
\text { line }\end{array}$ \\
\hline $\begin{array}{l}\text { Metaph- } \\
\text { orical }\end{array}$ & $0.406^{*}$ & & $0.736^{* *}$ & $0.770^{* *}$ & $\begin{array}{c}- \\
0.770^{* *}\end{array}$ & & \\
\hline Abstract & & $0.358^{*}$ & & & & $0.671^{*}$ & $-0.671^{*}$ \\
\hline $\begin{array}{c}\text { Landscap } \\
\mathrm{e}\end{array}$ & & & $-0.867 * *$ & & & & \\
\hline
\end{tabular}

Analysis of the data presented in table 5 shows that the metaphorical picture of the world is directly related to the increased size of the drawing $\left(, 406^{*}\right)$. For an Abstract picture of the world,there is a direct relationship with the index of originality of verbal creativity $\left(, 358^{*}\right)$, i.e. students who have an abstract picture of the world have a high verbal creativity and are able to create new things.

It was found that the image of the world of Conservatory students with a low level of nonverbal creativity has the following connections. For students with a Landscape view of the world,there is an inverse relationship with the uniqueness index $\left(-, 867^{* *}\right)$. We believe that in this case, the more students Express their landscape picture of the world, the less they are able to create something truly non-standard, unique, and show verbal creativity.

For students with a metaphorical picture of the world,there is a Direct link with the index of uniqueness of verbal creativity $\left(, 736^{* *}\right)$. In this case, we believe that Conservatory students with a low level of nonverbal creativity with a metaphorical picture of the world have a high level of verbal creativity, are able to overcome stereotypes at the final stage of mental synthesis and create something truly unique. They are characterized by the breadth of the field of associations. They are also characterized by a direct relationship with the increased size of the drawing $(, 770 * *)$ and a feedback relationship with the normal size of the drawing $(-, 770 * *)$.

For students with an Abstract picture of the world,there is a direct relationship with the position of the drawing on the sheet at the top $\left(, 671^{*}\right)$ and an inverse relationship with the position of the drawing on the paper at the middle line $\left(-, 671^{*}\right)$. This suggests that students with an abstract picture of the world have an inflated self-assessment.

For students with an average level of nonverbal creativity, it was found that the image of the world does not have significant correlations.

Describing the image of the world of students with a high level of nonverbal creativity, we can distinguish the following: 
We believe that students who have a metaphorical picture of the world are more extroverted.

Students who have an abstract picture of the world have a high level of creativity, are able to find non-standard solutions to problems, and are characterized by speech-thinking creativity.

Describing the image of the world of students with a low level of nonverbal creativity, we can distinguish the following:

The more pronounced the landscape picture, the less verbally creative students are.

Students with a metaphorical picture of the world have a high level of verbal creativity and are able to create new things.

Students with an abstract picture of the world have an inflated self-esteem, the more they have an abstract picture of the world, the less extraverts they have.

\section{Discussion}

So, students with a high level of nonverbal creativity have higher indices of originality and uniqueness, compared to students with a low level of nonverbal creativity. We believe that students with a high level of nonverbal creativity are able to create something new, unique, creatively approach problems, i.e. think outside the box.

Thus, music students are generally characterized by high nonverbal creativity compared to verbal creativity, which is due, according to Hennessey B. A., Amabile T. M. [10], Sternberg RJ. [4], to the peculiarities of the activities they perform.

We found that students with a high level of nonverbal creativity have higher values of the verbal creativity originality index compared to students with medium and low levels of nonverbal creativity. It can be concluded that students with a high level of nonverbal creativity tend to go beyond the problem, to find its original, unique solutions. It was also found that students with a high level of nonverbal creativity have higher indices of originality and uniqueness, compared to students with a low level of nonverbal creativity. In other words, we can say that students with a high level of nonverbal creativity are able to improve an object by adding details, produce a variety of ideas, respond to stimuli in a non-standard way, and find original, creative ways to solve nonverbal tasks assigned to them.

Describing the image of the world of students with a high level of non-verbal creativity, we can distinguish the following:

We believe that students who have a metaphorical picture of the world are more extroverted.

Students who have an abstract picture of the world have high verbal creativity, are able to find non-standard solutions to problems, and are characterized by speech-thinking creativity.

Describing the image of the world of students with a low level of nonverbal creativity, we can distinguish the following:

The more pronounced the landscape picture, the less verbally creative students are.

Students with a metaphorical picture of the world have a high level of verbal creativity and are able to create new things.

Students with an abstract picture of the world have high self-esteem; the more they have an abstract picture of the world, the less extroverts they are. 


\section{Conclusions}

In the course of our research, we have determined that the overall level of creativity of Conservatory students is at a high level. In General, the level of non-verbal creativity of Conservatory students is higher than the level of verbal creativity.

The conducted empirical research allows us to draw the following conclusions:

1. Students with a high level of nonverbal creativity have a more pronounced abstract picture of the world than students with a low level of nonverbal creativity. We believe that the majority of students with a high level of nonverbal creativity have an image of the world in the form of some abstract image, symbol, or sign. indicators Fig. These students are truly creative, which indicates the ability to improve the object by adding details, produce a variety of ideas, respond to stimuli in a non-standard way, and find original, creative ways to solve non-verbal tasks set for them.

2. students with an average level of non-verbal creativity are dominated by a landscape picture of the world. This indicates that the majority of students with an average level of nonverbal creativity present the image of the world in the form of a desired picture of their environment.

3. students with a low level of nonverbal creativity have a more pronounced landscape picture of the world than students with a high level of nonverbal creativity. These students have a low verbal creativity, i.e. there is a rather low ability to find a unique, creative solution to the tasks set, and in General there is a standard, stereotypical approach to the problem. Students with a landscape map of the world have a low level of verbal creativity. Students with a metaphorical picture of the world are highly creative, creative, and capable of creating new things. Students with an abstract picture of the world have high self-esteem.

\section{References}

1. J.P. Guilford, The Nature of Human Intelligence (McGraw-Hill, New York, 1967)

2. E.P. Torrance, Torrance. Tests of Creative Thinking: Norms-Technical Manual (Ginn, Lexington, MA, 1974)

3. R.J. Sternberg, American Psychologist 56, 360-362 (2001)

4. R.J. Sternberg, American Educational Research Journal 45, 150-165 (2008)

5. D. Hocevar, P. Bachelor, Handbook of creativity (Springer US, 1989)

6. B.N. Park, P. Byrnes, Roeper Review 6, 216-218 (1984)

7. H.B. Parkhurst, Journal of Creative Behavior 33, 1-21 (1999)

8. A. Belousova, J. Mochalova, O. Barsukova, M. Vyshkvyrkina, E. Kryschenko, N. Mozgovaya, T. Pavlova, J. Tushnova, INTED2017 Proceedings. 11th International Technology, Education and Development Conference (Valencia, 2017)

9. V. Pishchik, A. Belousova, L. Ryumshina, EDULEARN18 Proceedings. 10th International Conference on Education and New Learning Technologies (IATED, Palma, 2018) doi: 10.21125/edulearn.2018

10. B.A. Hennessey, T.M. Amabile, Creativity. Annual Review of Psychology 61, 569-598 (2010) doi:10.1146/annurev.psych.093008.100416

11. A. Belousova, G. Kozhukhar, V. Pishchik, 4th International Conference on Education Science and Development. ICESD 2019 (Shenzhen, 2019)

12. E. Virkkula, Nissilä Säde-Pirkko, CEPS Journal 7(3), 113-135 (2017)

13. A. Reid, D. Bennett, Proceedings of the 20th International Seminar of the ISME Commission on the Education of the Professional Musician (Belo Horizonte, 2014) 
14. V.N. Druzhinin, Psychology of general abilities (Yurayt Publishing House, Moscow, 2019)

15. E.S. Romanova, Graphic methods in practical psychology (AspectPress, Moscow, 2002)

16. A.L. Venger, Psychological Drawing Tests: An Illustrated Guide (VLADOS-PRESS Publishing House, Moscow, 2003)

17. A.D. Nasledov, Analysis and Interpretation of Data (Speech, St. Petersburg, 2007) 